\title{
Impressive thrombocytosis evolving in a patient with a BCR-ABL positive CML in major molecular response during dasatinib treatment unmasks an additional JAK2V617F
}

Friederike Pastore ${ }^{1,2^{*}}$, Stephanie Schneider ${ }^{1}$, Oliver Christ ${ }^{1}$, Wolfgang Hiddemann ${ }^{1,2}$ and Karsten Spiekermann ${ }^{1,2}$

\begin{abstract}
We present a case of a 42-year old female with the rare diagnosis of a myeloproliferative syndrome harboring both a BCR-ABL transclocation and a JAK2V617F mutation.

Initially diagnosed with a CML, the patient underwent treatment with imatinib followed by dasatinib. Despite a major molecular response, the patient developed a thrombocytosis. Molecular analyses revealed a heterozygous JAK2V617F mutation, which was detected retrospectively in the bone marrow at the time of CML diagnosis. This case underlines the complexity of MPS pathogenesis. For the clinician, a JAK2 mutational screening should be performed in CML patients without hematological response in the absence of BCR-ABL.
\end{abstract}

Keywords: BCR-ABL, JAK2V617F, CML, MPS

\section{Case presentation}

In March 2005 a 42-year old woman presented with a leukocytosis of $350 \mathrm{G} / \mathrm{l}$, a thrombocytosis of $498 \mathrm{G} / \mathrm{l}$ and an elevated lactate dehydrogenase (LDH) level of 2207 U/l. The differential blood count showed 47\% neutrophils, $14 \%$ myelocytes, $11 \%$ promyelocytes, $10 \%$ myeloblasts, $5 \%$ metamyelocytes, $5 \%$ eosinophils, $5 \%$ basophils and 3\% lymphocytes.

The diagnosis of a typical chronic myeloid leukemia (CML) was established after detection of an aberrant karyotype $46, \mathrm{XX}, \mathrm{t}(9 ; 22)(\mathrm{q} 34 ; \mathrm{q} 11)$ in all 25 metaphases and the presence of the BCR-ABL-rearrangement (98\%) in the bone marrow aspirate by FISH. The quantitative BCR-ABL/ABL ratio determined by RT-PCR was 53.0. The spleen was enlarged with $22.5 \mathrm{~cm}$. The patient was classified as low risk according to Sokal [1] and Hasford [2] risk scores for survival.

After an initial treatment with hydroxyurea resulting in a rapid cytoreduction with an initial tumor lysis

\footnotetext{
* Correspondence: Friederike.Pastore@med.uni-muenchen.de

'Laboratory for Leukemia Diagnostics, Department of Internal Medicine III, University Hospital Munich - Campus Grosshadern, Munich, Germany ${ }^{2}$ Clinical Cooperative Group, Pathogenesis of Acute Leukemia, Helmholtz Center, Munich, Germany
}

syndrome therapy was changed to imatinib $(400 \mathrm{mg} /$ day) in April 2005.

Under the treatment with imatinib the patient achieved a complete hematological remission within two months. Since cytogenetic and molecular remission was not obtained even after one year of therapy with imatinib, a mutation analysis of BCR-ABL was performed in October 2006, which revealed no evidence for point mutations within the BCR-ABL kinase domain. After an initial decrease, the BCR-ABL/ABL ratio continuously increased from 3.4 to 33.3 in February 2009. The patient was recommended to increase the dose of imatinib, which she declined.

In June 2009, the patient developed a hematological relapse of the CML with leukocytosis (24 G/l), thrombocytosis (853 G/l) and elevated LDH level (290 U/l). Interphase FISH detected 59\% BCR-ABL positive cells and the $\mathrm{BCR}-\mathrm{ABL} / \mathrm{ABL}$ ratio was markedly elevated (48.13). Therapy was changed to a second line regimen with dasatinib (Figure 1).

Within three months of therapy with dasatinib, a hematological response with normalization of the white blood count (WBC) and platelet count, as well as a complete cytogenetic (no BCR-ABL positive nuclei in 

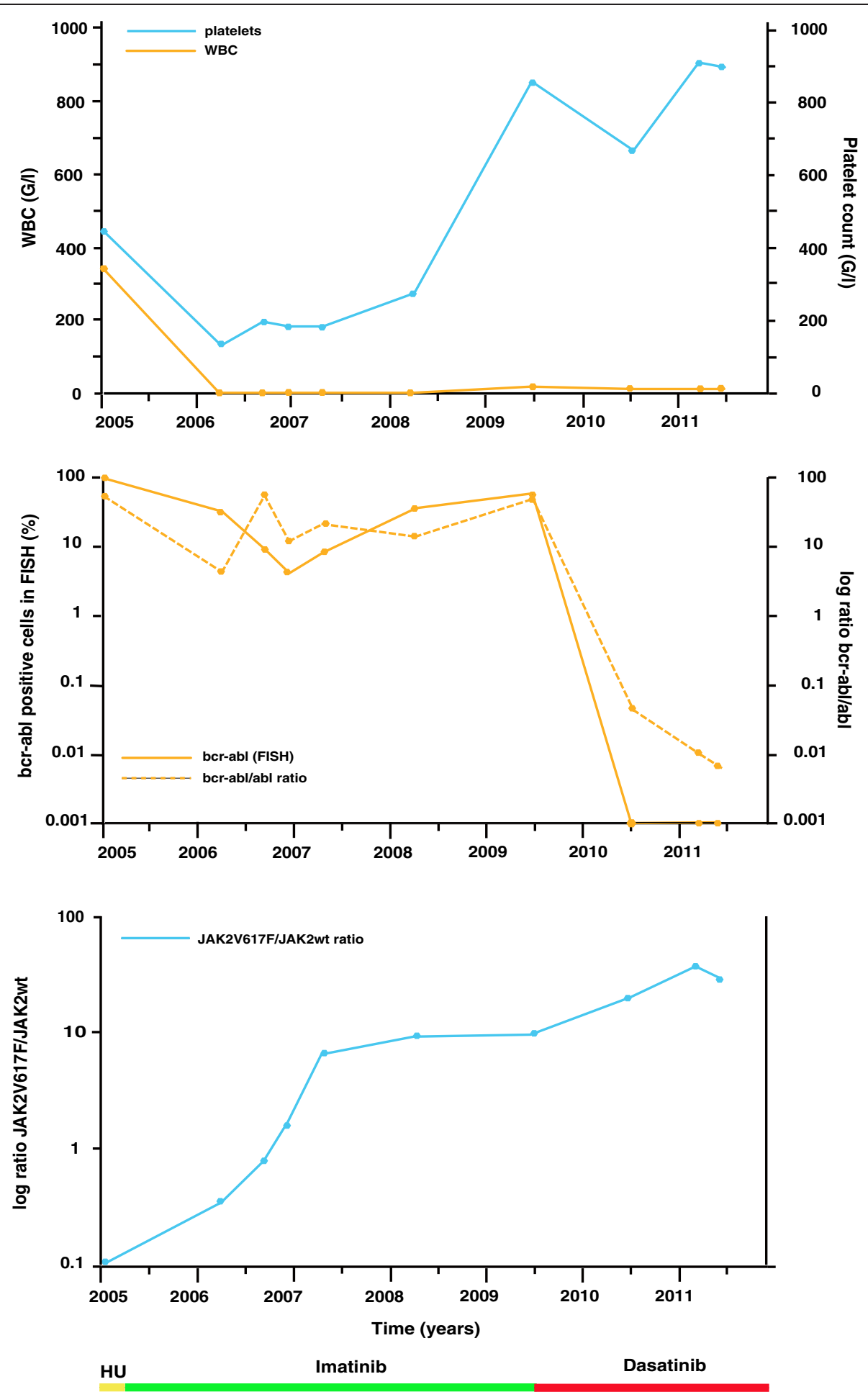

Figure 1 Summary of blood counts, molecular analyses and cytoreductive therapy in a patient with a CML with JAK2V617F clonal evolution under treatment with imatinib and dasatinib. 
FISH) and a partial molecular remission (BCR-ABL/ ABL ratio dropped to 0.6 ) was recorded.

A major molecular response, with a normal karyotype and a BCR-ABL/ABL ratio $<0.1(0.04)$ in the quantitative RT-PCR was diagnosed in October 2010.

Until March 2013 repeated molecular and cytogenetic analyses showed a constant complete cytogenetic and major molecular remission.

Despite the absence of the Philadelphia chromosome, the patient developed and retained a marked thrombocytosis and elevated LDH levels again since February 2010.

Therefore, a JAK2-V617F mutation analysis was performed in October 2010, which demonstrated a heterozygous V617F [3].

The amount of the mutated JAK2-allel was quantified with the MutaQuant ${ }^{\text {TI }}$ kit from Ipsogene. Retrospective analyses of gDNA from peripheral blood or bone marrow samples from the first diagnosis until June 2010 revealed that the JAK2 mutant allel had already been present in the bone marrow at first diagnosis at a very low level (ratio JAK2V617F/JAK2wt : 0.122).

The amount of JAK2 mutant allel was constant in 2006 and showed a rapid increase in 2007 (from 1.091 in January to 6.754 in May) under treatment with imatinib. In June 2006, when the CML relapse was diagnosed and therapy was changed to dasatinib, the JAK2V617F/JAK2wt ratio was 9.9 and further increased since then to 30.3 in May 2011. Thus, both, BCR-ABL and JAK2V617F coexisted simultaneously. Whereas leucocytosis was due to genetic abnormalities, persistant thrombocytosis was mainly caused by the JAK2V617F.

\section{Conclusion and discussion}

We present a patient with a BCR-ABL positive CML who achieved a major molecular response after second line treatment with dasatinib. Occurrence of an impressive thrombocytosis and elevated LDH levels in the absence of BCR-ABL led to the diagnosis of an additional JAK2V617positive clone. Retrospectively, the JAK2V617F mutant was already detectable at a very low level simultaneously to BCR-ABL at first diagnosis of CML. This is a rare case unmasking a JAK2V617F-positive clone in a patient with a BCR-ABL positive CML.

JAK2 is a tyrosine kinase that plays an important role in the signalling pathways of myeloid hematopoietic cells. A single acquired activating point mutation in JAK2 (V617F) occurs in the majority of BCR-ABL negative MPS such as ET, PV and OMF [4-7], but is only rarely found in BCRABL positive CML $[8,9]$.

The hypothesis, that BCR-ABL and JAK2V617F are mutually exclusive [8] has been disproved in the last few years.

There have been reports about patients with a previous history of a JAK2V617F positive polycythemia vera (PV) [10-12], ET [13] or osteomyelofibrosis (OMF) [14] that developed a BCR-ABL positive CML and other patients that suffered a CML who developed features of a PV $[15,16]$, an ET [17] or an OMF [18,19].

The JAK2V617F mutation was shown to precede the acquisition of BCR-ABL $[10,14]$, co-occur with $[16,19,20]$ and also succeed $[15,21]$ the BCR-ABL fusion transcript.

In the published literature data are still controversial concerning the aspect if Philadelphia chromosome negative MPS and CML develop as separate diseases originating from different stem cells, or if these entities evolve from a mutual cell of origin by the acquisition of JAK2V617F and the BCR-ABL fusion gene at different time points.

Some authors favor the hypothesis, that a single subclone of progenitor cells carrying a JAK2V617F successively acquires the BCR-ABL translocation [10]. Those cells acquire a proliferative advantage, but disappear when exposed to imatinib. In contrast, the clone harboring JAK2V617F only will not be sensitive to imatinib.

Other models postulate that a JAK2V617F and the BCR-ABL fusion derive independently parallel from susceptible polyclonal stem cells $[15,22-24]$ or might be preceeded by another independent genetic hit (founder mutation) which predisposes to their acquisition [18].

In our patient, at initial diagnosis a JAK2V617F was detectable at a very low level whereas the BCR-ABL clone was already $100 \%$ of the CML clone. Considering the mere frequencies this suggests that the two mutations might have arisen independently in different bone marrow cells.

Nevertheless, applying the hypothesis of Bocchia et al. [10] this does not exclude the possibility that the BCR-ABL positive clone might have represented a sub-clone of JAK2V617F mutated cells which had gained a growth advantage.

Under therapy with imatinib the JAK2 mutant level increased suggesting a growth advantage of JAK2V617F positive/BCR-ABL negative cells in relation to JAK2V617F positive/BCR-ABL positive cells which might have been at least to some degree antagonized by imatinib. These observations are in line with the fact that CML therapy with imatinib was shown to reveal Philadelphia chromosome negative clonal disorders in more than $10 \%$ of CML patients [25].

Finally, therapy with dasatinib might have eliminated the JAK2F617F-positive/ BCR-ABL positive clone. The suppression of the BCR-ABL clone might have facilitated growth of the JAK2V617F-positive cells without the BCR-ABL fusion that were unaffected by dasatinib. This theory is supported by continuously rising levels of the JAK2V617F/JAK2wt ratio and progressive thrombocytosis and leukocytosis in our patient. This is in line with the so called "gene dosis hypothesis" meaning that JAK2V617F expression level correlate with the number of involved cell lines and thus the type of disease (low level - > ET; high level - > PV) [26,27]. The increase of platelets to $>1000 \mathrm{G} / \mathrm{l}$ was followed by an increase of leukocytes. 
Our data suggest the co-occurence of different clones carrying either JAK2V617F or BCR-ABL. Yet it does not exclude the possibility of BCR-ABL/JAK2V617F doublepositive sub-clones.

According to our hypothesis, the BCR-ABL clone which showed an initial clonal pre-dominance was successfully reduced by treatment with dasatinib which unmasked clinical features attributed to JAK2V617F-positive disease.

These results represent the complex pathogenesis of MPS and demonstrate the possibility of overlaps or coexistences between the BCR-ABL positive and negative MPS. For the clinician, we recommend to analyze the JAK2 mutation status in patients with an established diagnosis of CML who develop myeloproliferation and/or disease progression despite molecular remission of the CML.

\section{Consent}

Written informed consent was obtained from the patient for publication of this Case report and any accompanying images. A copy of the written consent is available for review by the Editor-in-Chief of this journal.

\section{Competing interests}

The authors declare that they have no competing interests.

\section{Authors' contributions}

FP wrote the paper, performed analysis of data and interpretation of data. SS performed the cytogenetic and molecular analyses, analysis of data and interpretation of data. OC was involved in the medical care of the patient performed analysis of data and interpretation of data. WH designed the study and performed interpretation of data. KS designed the study and performed interpretation of data. All authors read and approved the final manuscript.

Received: 24 August 2013 Accepted: 31 August 2013

Published: 5 September 2013

\section{References}

1. Sokal JE, Cox EB, Baccarani M, Tura S, Gomez GA, Robertson JE, Tso CY, Braun TJ, Clarkson BD, Cervantes F: Prognostic discrimination in "goodrisk" chronic granulocytic leukemia. blood 1984, 63:789-799.

2. Hasford J, Pfirrmann M, Hehlmann R, Allan NC, Baccarani M, Kluin-Nelemans JC, Alimena G, Steegmann JL, Ansari H: A new prognostic score for survival of patients with chronic myeloid leukemia treated with interferon Alfa. Writing committee for the collaborative CML prognostic factors project group. J Natl Cancer Inst 1998, 90:850-858.

3. Campbell PJ, Scott LM, Buck G, Wheatley K, East CL, Marsden JT, Duffy A, Boyd EM, Bench AJ, Scott MA, Vassiliou GS, Milligan DW, Smith SR, Erber WN, Bareford D, Wilkins BS, Reilly JT, Harrison CN, Green AR, United Kingdom Myeloproliferative Disorders Study Group, Medical Research Council Adult Leukaemia Working Party, Australasian Leukaemia and Lymphoma Group: Definition of subtypes of essential thrombocythaemia and relation to polycythaemia Vera based on JAK2 V617F mutation status: a prospective study. Lancet 2005, 366:1945-1953.

4. Kralovics R, Passamonti F, Buser AS, Teo S-S, Tiedt R, Passweg JR, Tichelli A, Cazzola M, Skoda RC: A gain-of-function mutation of JAK2 in myeloproliferative disorders. N Engl J Med 2005, 352:1779-1790.

5. Levine RL, Wadleigh M, Cools J, Ebert BL, Wernig G, Huntly BJP, Boggon TJ, Wlodarska I, Clark JJ, Moore S, Adelsperger J, Koo S, Lee JC, Gabriel S, Mercher T, D'Andrea A, Fröhling S, Döhner K, Marynen P, Vandenberghe $P$, Mesa RA, Tefferi A, Griffin JD, Eck MJ, Sellers WR, Meyerson M, Golub TR, Lee SJ, and Gilliland DG: Activating mutation in the tyrosine kinase JAK2 in polycythemia vera, essential thrombocythemia, and myeloid metaplasia with myelofibrosis. Cancer Cell 2005, 7(4):387-397.
6. James C, Ugo V, Le Couédic J-P, Staerk J, Delhommeau F, Lacout C, Garçon L, Raslova H, Berger R, Bennaceur-Griscelli A, Villeval JL, Constantinescu SN, Casadevall $\mathrm{N}$, and Vainchenker W: A unique clonal JAK2 mutation leading to constitutive signalling causes polycythaemia vera. Nature 2005, 434(7037):1144-1148.

7. Baxter EJ, Scott LM, Campbell PJ, East C, Fourouclas N, Swanton S, Vassiliou GS, Bench AJ, Boyd EM, Curtin N, Scott M, Erber WN, Green AR: Cancer Genome Project: Acquired mutation of the tyrosine kinase JAK2 in human myeloproliferative disorders. Lancet 2005, 365(9464):1054-1061.

8. Jelinek J, Oki Y, Gharibyan V, Bueso-Ramos C, Prchal JT, Verstovsek S, Beran M, Estey E, Kantarjian HM, Issa J-PJ: blood 2005, 106:3370-3373.

9. Scott LM, Campbell PJ, Baxter EJ, Todd T, Stephens P, Edkins S, Wooster R, Stratton MR, Futreal PA, Green AR: The V617F JAK2 mutation is uncommon in cancers and in myeloid malignancies other than the classic myeloproliferative disorders. blood 2005, 106:2920-2921.

10. Bocchia M, Vannucchi AM, Gozzetti A, Guglielmelli P, Poli G, Crupi R, Defina $\mathrm{M}$, Bosi A, Francesco L: Insights into JAK2-V617F mutation in CML. Lancet Oncol 2007, 8:864-866

11. Pingali SRK, Mathiason MA, Lovrich SD, Go RS: Emergence of chronic myelogenous leukemia from a background of myeloproliferative disorder: JAK2V617F as a potential risk factor for BCR-ABL translocation. Clin Lymphoma Myeloma 2009, 9:E25-E29.

12. Pieri L, Spolverini A, Scappini B, Occhini U, Birtolo S, Bosi A, Albano F, Fava C, Vannucchi AM: Concomitant occurrence of BCR-ABL and JAK2V617F mutation. blood 2011, 118:3445-3446.

13. Curtin NJ, Campbell PJ, Green AR: The Philadelphia translocation and preexisting myeloproliferative disorders. Br J Haematol 2005, 128:734-736.

14. Jallades L, Hayette S, Tigaud I, Johnston A, Coiffier B, Magaud J-P, Ffrench $\mathrm{M}$ : Emergence of therapy-unrelated CML on a background of BCR-ABLnegative JAK2V617F-positive chronic idiopathic myelofibrosis. Leuk Res 2008, 32:1608-1610.

15. Tefferi A, Levitt R, Lasho TL, Knudson RA, Ketterling RP: Postimatinib therapy emergence of a new JAK2V617F clone and subsequent development of overt polycythemia vera in a patient with chronic myelogenous leukaemia. Eur J Haematol 2010, 85:86-87.

16. Inami M, Inokuchi $K$, Okabe M, Kosaka F, Mitamura $Y$, Yamaguchi H, Dan K: Polycythemia associated with the JAK2V617F mutation emerged during treatment of chronic myelogenous leukemia. Leukemia 2007, 21:1103-1104.

17. Krämer A, Reiter A, Kruth J, Erben P, Hochhaus A, Müller M, Cross NC, Jones $A V$, Ho AD, Hensel M: JAK2-V617F mutation in a patient with Philadelphia-chromosome-positive chronic myeloid leukaemia. Lancet Oncol 2007, 8(7):658-660.

18. Nadali F, Ferdowsi Sh, Karimzadeh P, Chahardouli B, Einollahi N, Mousavi SA, Bahar B, Dargahi H, Alimoghaddam K, Ghavamzadeh A, Ghaffari SH: JAK2V617F Mutation and Philadelphia Positive Chronic Myeloid Leukemia. IJHOSCR 2009, 3(3):43-45.

19. Hussein K, Bock O, Seegers A, Flasshove M, Henneke F, Buesche G, Kreipe $\mathrm{HH}$ : Myelofibrosis evolving during Imatinib treatment of a chronic myeloproliferative disease with coexisting BCR-ABL translocation and JAK2V617F mutation. blood 2007, 109:4106-4107.

20. Pahore Z-A-A, Shamsi TS, Taj M, Farzana T, Ansari SH, Nadeem M, Ahmad M, Naz A: JAK2V617F mutation in chronic myeloid leukemia predicts early disease progression. J Coll Physicians Surg Pak 2011, 21:472-475.

21. Nadali F, Sh F, Karimzadeh P, Chahardouli B: JAK2-V617F Mutation and Philadelphia positive chronic myeloid leukemia. IJHOSCR 2009, 3(3):43-45.

22. Tefferi A, Lasho TL, Patnaik MM, Finke CM, Hussein K, Hogan WJ, Elliott MA, Litzow MR, Hanson CA, Pardanani A: JAK2 Germline genetic variation affects disease susceptibility in primary myelofibrosis regardless of V617F mutational status: nullizygosity for the JAK2 46/1 haplotype is associated with inferior survival. Leuk 2010, 24:105-109.

23. Schaub FX, Jäger $R$, Looser $R$, Hao-Shen H, Hermouet $S$, Girodon F, Tichelli A, Gisslinger H, Kralovics R, Skoda RC: Clonal analysis of deletions on chromosome $20 q$ and JAK2-V617F in MPD suggests that del20q acts independently and is not one of the predisposing mutations for JAK2V617F. blood 2009, 113:2022-2027.

24. Schaub FX, Looser R, Li S, Hao-Shen H, Lehmann T, Tichelli A, Skoda RC: Clonal analysis of TET2 and JAK2 mutations suggests that TET2 can be a late event in the progression of myeloproliferative neoplasms. blood 2010, 115:2003-2007.

25. Bumm T, Müller C, Al-Ali H-K, Krohn K, Shepherd P, Schmidt E, Leiblein S, Franke C, Hennig E, Friedrich T, Krahl R, Niederwieser D, Deininger MWN: 
Emergence of clonal cytogenetic abnormalities in Ph- cells in some CML patients in cytogenetic remission to imatinib but restoration of polyclonal hematopoiesis in the majority. blood 2003, 101:1941-1949.

26. Lacout C, Pisani DF, Tulliez M, Gachelin FM, Vainchenker W, Villeval J-L: JAK2V617F expression in murine hematopoietic cells leads to MPD mimicking human PV with secondary myelofibrosis. blood 2006, 108:1652-1660.

27. Tefferi A, Pardanani A: Mutation screening for JAK2V617F: when to order the test and how to interpret the results. Leuk Res 2006, 30:739-744.

doi:10.1186/2162-3619-2-24

Cite this article as: Pastore et al:: Impressive thrombocytosis evolving in a patient with a BCR-ABL positive CML in major molecular response during dasatinib treatment unmasks an additional JAK2V617F.

Experimental Hematology \& Oncology 2013 2:24.

\section{Submit your next manuscript to BioMed Central and take full advantage of:}

- Convenient online submission

- Thorough peer review

- No space constraints or color figure charges

- Immediate publication on acceptance

- Inclusion in PubMed, CAS, Scopus and Google Scholar

- Research which is freely available for redistribution 























































































































































































